\title{
Road design intervention based on traffic accident dynamics: a forensic intelligence approach
}

\author{
C. A. Andrade ${ }^{1,2}$, B. Telles ${ }^{1,2}$, M. S. Sercheli ${ }^{1,2}$, N. M. Kawano ${ }^{1,2}$, \\ R. M. Soares ${ }^{1}$, A. N. Vicente ${ }^{1,2}$, W. X. Camargo Filho ${ }^{1,2}$ \\ \& J. A. Gomes ${ }^{1,2}$ \\ ${ }^{1}$ Criminalistics Institute, Civil Police of the Federal District (PCDF), \\ Brasília (DF), Brazil \\ ${ }^{2}$ Ilaraine Acácio Arce Criminalistics Expert Foundation \\ (FPCIAA), Brazil
}

\begin{abstract}
Traffic accidents in the Brazilian Federal District historically have killed more than 400 people per year. With the purpose of reducing this number and saving lives, we investigated all fatal car crashes which occurred in 2012, proposing solutions for the most dangerous areas. However, the focus of this paper is to study in detail the worst hot spot, located at the intersection formed by two highways (BR-251 and DF-473). To do this, we used forensic data to reconstruct the collisions, which allowed us to identify some contributing factors for these events, namely: the lack of speed control devices, inadequate signs and a route that provides the cross-flow without safety conditions. Besides, all collisions occurred in this crossroad had very similar car crash dynamics. Thus, we suggested two possible engineering road interventions: $(i)$ an emergency intervention: placement of lines to stimulate the speed reduction, before a transversal bump; and (ii) a definitive intervention, more expensive and longest deployment engineering: the adoption of a roundabout preceded by an electronic speed control device with the necessary traffic signs adaptation. We emphasize that the Prosecution Service of the Federal District and Territories supported this work in order to have qualified technical information to demand efficient actions from authorities responsible for the roads.
\end{abstract}

Keywords: intelligence-led policing, forensic intelligence, environmental criminology, road intervention, transportation safety and security. 


\section{Introduction}

According to reports published by the World Health Organization (WHO), more than 1.2 million people die each year on the roads around the world, representing the eighth leading cause of death, the great cause among young people aged 1529 years. If nothing is done, the WHO estimates that in 2020 traffic accidents will be the third largest public health problem worldwide, second only to coronary heart disease and depression. However, nowadays it is estimated that over $90 \%$ of the recorded occurrences are in developing countries, like Brazil, in which the transit already represents the fifth leading cause of death [1, 2].

Faria and Braga [3] states that the basic objectives of a work directed to the increase of traffic safety conditions are: $(i)$ lower overall numbers of deaths and injuries; (ii) reduce the risk on these roads; (iii) reduce the consequences of accidents. For each of these objectives it can have a set of appropriate measures. For example, for the first group, it is possible to make use of measures to encourage the replacement of individual modes of transport by collective ones, which are safer, such as the subway; for the second group of objectives, the government can direct its efforts to traffic control, to the identification and treatment of critical points in the road network and to the traffic education. Finally, for the last set of objectives, encouraging the use of equipment such as seat belt and a better first respond (rescue) for the victims are a way to lessen the severity of claims.

Following this guidance and focusing the reduction of deaths caused by traffic accidents in the Federal District of Brazil, Ilaraine Acácio Arce Criminalistics Expert Foundation (FPCIAA) signed a technical cooperation [4] with Prosecution Service of the Federal District and Territories (MPDFT), the Brazilian public agency that has the responsibility, among others, to charge actions from the authorities responsible for transit. In this agreement, the FPCIAA was responsible for investigate all accidents resulting in deaths on the roads of the Federal District of Brazil, in 2012. As a result of this study, we identified the problems, set the priority objective to be achieved and, from this, we chose the most appropriate measures to address the problem in order to base the actions to be taken by MPDFT in the fight against this epidemic issue.

Within the global study, we identify the general characteristics of events separated into two categories: pedestrian accidents [5] and other types of collisions [6]. However, this work is limited to the worst critical point detected in the research of the collisions: the intersection formed by the federal highway BR-251 and the state highway DF-473, located in Administrative Region of São Sebastião, Federal District of Brazil.

\section{Materials and methods}

\subsection{Theoretical references}

A very current tool that have a wide application in Forensic Science is the Forensic Intelligence. With this tool, the Forensic Scientist leaves the reactive position 
(only acting under provocation and in order to answer the questions of the requesting authority) and takes proactive stance, transforming their data into information and that information into useful knowledge for the arrest of criminals and prevention of crime practices. We could say that intelligence is the timely, accurate and usable processed information [7].

Usually, Police Departments use systems and models to make decisions. Nevertheless, it is increasingly recognized that vast information about the criminal environment and criminal activity exist and can be used as a key element (when analyzed) in the decision-making process. A relatively new model, intelligenceled policing recognizes that the rigorous treatment of information and the rapidity of its dissemination are essential aspects of that process. Intelligence-led policing is a conceptual framework for management policing and an approach to organize information that allows police agencies to better understand crime problems (in particular how, when and why crimes occurs) [8].

For Morelato et al. [9], forensic intelligence plays a new role in Forensic Science by extending its approach "case by case" in a more phenomenological and proactive approach. The forensic intelligence emerges from trace evidences that when extracted, analyzed and interpreted, generate timely information with the objective of supporting information processes (for example, the strategic, tactical and operational levels), all this is done for the police and security managers to make better decisions. Their role is not limited to investigations or to confirm hypotheses suggested by conventional police investigation, but also to provide proactive insights into criminal activity and to support the raising of relevant hypotheses.

The repetitive nature of the criminal activity requires dynamic management of data related to the analyzed cases, which would facilitate the connection among cases. Forensic intelligence is based on the ability to analyze, categorize, store, and relate trace evidences systematically and in a timely manner.

Traffic accidents are actually a kind of crime and have this repetitive nature. In many cases it is possible to foresee and avoid them, if known the " $3 \mathrm{~W}$ " (when and where happens, who are involved) and how.

Two other theories to support the implementation of Forensic Intelligence in this case are Routine Activities Theory and Crime Pattern Theory [10].

The first one says that for the crime occurrence there must be convergence of time and space in at least three elements: a motivated offender, a suitable target and the absence of a guardian able to prevent the crime [11]. You can apply this theory as follows: a motivated offender and a vulnerable target in an environment (an environment that provides the exact conditions under which the accident occurs). Thus, a traffic accident can be prevented if both the target and the site does not offer opportunities for a specific offense to occur and if the perpetrator is restrained from unlawful activities.

The second one states that crimes are grouped into patterns, such as violation types, procedure, location, people involved, time and events. In addition, there is growing evidences that crimes are repeated and more or less distributed within the following groups: offenders, victims/targets and places (hot spots - hot crime areas). According to this theory, a small number of causes $(20 \%)$ is responsible 
for a large proportion of results/effects ( $80 \%)$. In other words, $20 \%$ of the accidents sites account for $80 \%$ of these crimes (accidents). Thus, efforts and resources should be concentrated in accordance with the reality of crime, to achieve the best results in terms of prevention.

According to these theories, it was possible to identify a hot spot where the high incidence of accidents with death is due to problems in the road designs.

In this sense, according to the environmental criminology theory, it is possible to realize patterns and elements in these hot spots, which, once understood, could aid in preventing.

Despite the existence of several established methods in the technical literature in order to determine points, segments or even critical areas (numerical, statistical methods, potential safety index, conflict analysis technique and road safety audit) and then make the corrective engineering measures, we chose to use the Criminalistics Institute of Brazilian Federal District database, about the occurrence of traffic accidents with victims in 2012. The choice of this methodology was due to the fact that it is possible to work with real and specific data of the selected location, with access including the study of determinant causes of all accidents at this point, the cause of death and concentration of alcohol, cocaine and marijuana in the blood of the victims (provided by Medical Legal Institute of Brazilian Federal District).

For the case in question, we know where they occur, remain to know how and why, so that effective mitigation measures can be taken.

\subsection{Intersection formed by the BR-251 and DF-473 highways}

The critical section in question, with considerable number of accidents, all with similar dynamics, is the intersection showed in Figure 1. The BR-251 highway is a known route of transportation of agricultural production and therefore frequented by cargo vehicles, which usually travels with a speed above of the maximum allowed for the site. The DF-473 highway, in turn, is an important access to the Administrative Region of São Sebastião, favoring large input and output of drive vehicles, which causes the cross-flow at these roads.

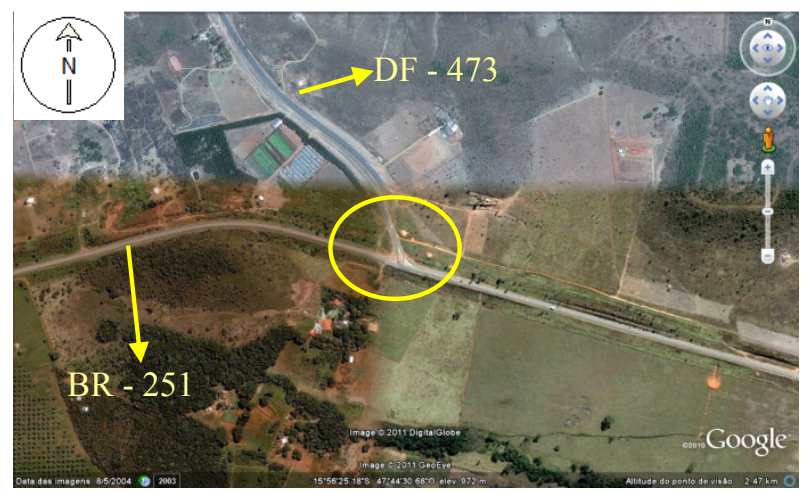

Figure 1: Satellite image, by Google Earth. 
The BR-251 highway, at the examined section, consists of an asphalt two-way lane, one lane for each traffic direction, separated by double yellow continuous line. The road has a straight shape, with a total width of 6.7 meters and, when considering the direction west - east (reference direction), it has a declivity and it contains a lane of deceleration/acceleration in the right side followed by the margin designed to vehicles that enter/leaves the DF-473 highway. When considering the reference direction, to the left side of the road there is a deceleration lane, which allows vehicles from the east-west lane of the BR-251 to turn to the DF-473 highway.

It should be noted that the DF-473 highway has a bump in the section, leading up to the intersection, causing the vehicles that come from there to have to reduce their speed in this area, but we highlight the vanished marks on the asphalt (Figure 2). Other important aspect to note is related to the lack of speed control devices on the BR-251. The track has only one such sequence from the maximum permitted speed signal plates $(80 \mathrm{~km} / \mathrm{h} \rightarrow 60 \mathrm{~km} / \mathrm{h} \rightarrow 40 \mathrm{~km} / \mathrm{h})$, and no physical device to control and/or reduce speed.

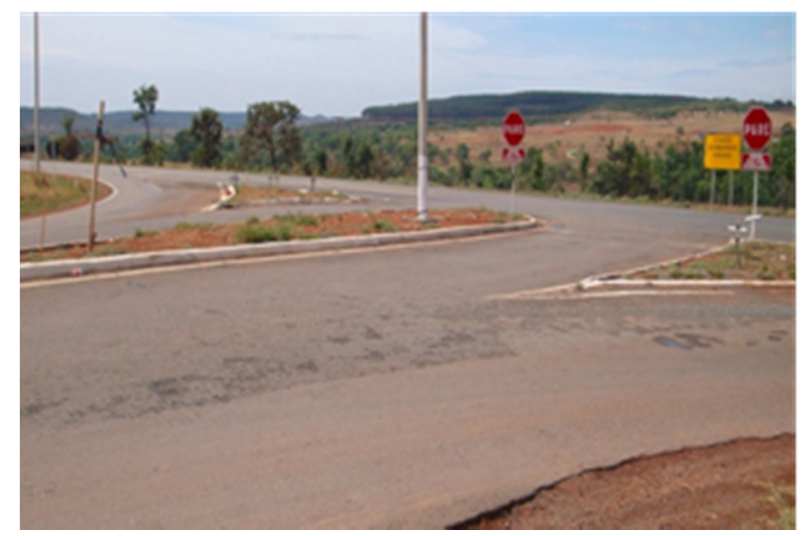

Figure 2: Intersection formed by the BR-251 and DF-473 highways.

Analyzing these accidents, we verified that all accidents has very similar dynamics: $(i)$ vehicles from the BR-251 towards west-east access the shoulder in order to enter on the DF-473; however, when performing the operation they are intercepted by vehicles traveling in the same direction, often speeding $(i i)$ vehicles from the DF-473 wanting to access the BR-251 towards east-west, when entering the highway they are intercepted by vehicles that travel there, almost always speeding.

\section{Discussion}

Considering the techniques for the prevention of situational crime [12], the adoption of measures to increase the effort of drivers committing the same offense pattern would be the adoption of speed bumps; to decrease the reward, would be 
the installation of electronic speed control; and to reduce the provocations, would be the breaking of the straight track layout.

The shoulder (which functions as the deceleration lane) is precarious and there is no signal "Give preference" for vehicles that want to stop on the BR-251, towards east-west, and wait for an opportunity to enter the DF-473.

For this section, we suggest two interventions. The first suggestion is a simpler solution, less expensive and easy to deploy, is the application of signals of stimulus lines to reduce speed and two cross-type bumps, signaling for the use of the shoulder and the installation of a plate "Give preference", named R2, according to the Brazilians laws [10]. The second proposal is a larger engineering measure, it is more costly from a financial point of view and a little longer to deploy, is the construction of a roundabout with electronic barriers.

\subsection{Signals of stimulus lines to reduce speed (LRV) and two cross-type bumps}

The first proposal, of emergency nature, suggests the implementation of two crosstype bumps on the BR-251 and signals of stimulus lines to reduce speed prior to them.

To calculate the application of the LRV, it was used the Brazilian Manual of Traffic Sign - Volume IV [13]. The first feature to be calculated is the thickness of the strip according to the desired speed along the path. The transit authority regulates the maximum speed of $40 \mathrm{~km} / \mathrm{h}$ in the intersection area, so the thickness of the band should be $0.20 \mathrm{~m}$. The equations used for sizing the stimulus lines based on the desired speed are also included in the same Manual volume.

Further to the LRV transversal bumps must be installed. To install this device it has been used, as a theoretical reference, the Resolution \#39 of 1998 CONTRAN [14]. As recommended by the Brazilian Manual of Traffic Sign [13], the LRV at this rate of reduction should be located 2.0 meters before each bump. The bumps must be designed according to the characteristics of the road, and, in the present study, the device to be used is the type II device, with a length of $3.70 \mathrm{~m}$ and a maximum height of $0.10 \mathrm{~m}$ [14].

Regarding the signal regulation, it should be placed, towards possessing the bump, the Plate A-18 on the side of the spine according to the resolution. A sketch of this suggestion is the solution shown in Figure 3. Note that the implementation of speed bumps on highways can contribute to other types of accidents, including

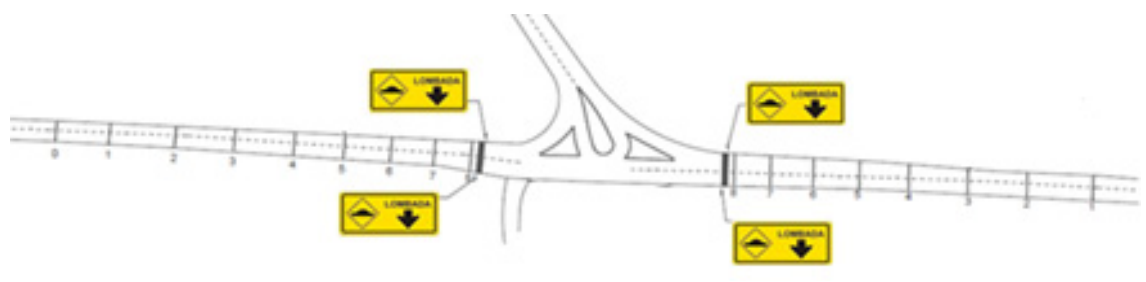

Figure 3: Sketch of first solution suggested. 
loss of vehicle control. However, as already mentioned, this is an emergency measure before proceeding to the implementation of electronic surveillance equipment, considered the second suggestion of this work.

\subsection{Electronic speed control and roundabout}

The second suggestion for this critical point is the implementation of an electronic barrier for speed control and restructuring the road with the construction of a roundabout in the intersection.

Regarding the electronic barrier, the first step was to determine how far it should be installed. According to Alencar and Freitas [15], the zone of influence of the electronic barrier is 100 meters, and this value is used for barrier installation in this proposal.

As to the roundabout, it should be noted that we do not have the necessary data about the road to do the project. After analyzing the Manual of use and configuration of roundabouts in roads outside urbanized areas of the DER/SC [16], we found out that it is necessary to have the data of traffic volume to calculate the roundabout capacity and consequently many other components such as island size, entrance angle, the track width, etc.

About the necessary signaling for the roundabout, consulting the Brazilian Manual of Traffic Sign - Volume I [17], to determine the vertical signaling, in the case that the roundabout "flow direction at the roundabout", it should be used the signal named plate R-33, which is adopted at a distance of $10 \mathrm{~m}$ for this kind of road. As for the vertical signal warning the roundabout, the needed plate type is the A-12, warning of the intersection in a circle, according to the Brazilian Manual of Traffic Signs, Volume II [18]. A sketch of the final solution of the second suggestion is shown in Figure 4.

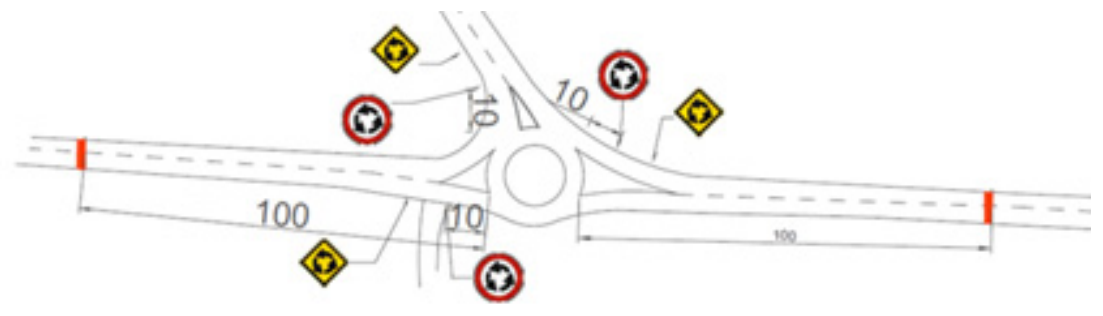

Figure 4: Sketch of the second solution suggested.

\section{Conclusions}

The studies allowed to define the junction formed by the BR-251 and DF-473 highways as a critical point of the occurrence of traffic accidents more severe, due to the high incidence of cases with fatal victims.

As the completion of this work, we have suggested two solutions to the critical point: the roundabout implantation preceded by electronic speed monitoring 
equipment on the BR-251 (as a definitive solution) and implementation of two transversal speed-bumps on the BR-251 with stimulus lines to reduce speed (as an emergency solution).

However, after receiving the reports from FPCIAA, the MPDFT motivated the transit authority responsible for the BR-251 to take steps in this regard and the transit authority decided to adopt a third solution, different from the suggestions presented here (Figure 5). The implemented solution was the duplication of the BR-251 in the intersection area, with the placement of double return in the median of the road. This solution is such a good solution, which proves that the authorities can make road intervention, after motivated, and are not obligated to follow suggestions, but can adopt as good as the suggested solutions to solve chronic problems.

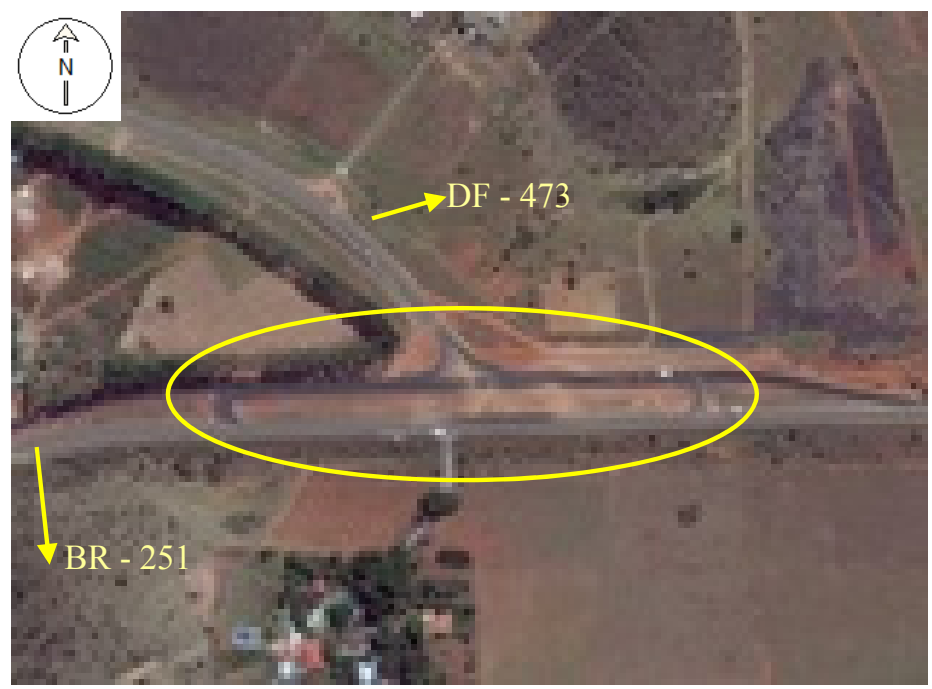

Figure 5: Satellite image, by Google Earth.

Additionally, we suggest that the professionals directly involved in traffic accidents (Military Police, Civil Police, Criminal Experts, CSIs, Traffic Agents, Federal Highway Police, etc.), that have the technical and scientific knowledge, as well as hold the statistics related to traffic accidents, use these real data (as an alternative to existing methods for the determination of points, segments and critical areas for corrective engineering actions), and with these, they could analyze the factors associated with their occurrence in order to contribute to prevention work, acting together (preferably) or referring studies and contributions to the agency with circumscription on the road. As state Ribaux et al. [7], the creation of crime analysis unites can improve the law enforcement, especially in allocation of resources in the most significant problems. These professionals could compose this especial unit, focusing in preventions and saving lives. Thus, the responsible agencies could: (i) promote actions to improve circulation and road safety; (ii) develop strategies that seek to reduce deaths and injuries in traffic; 
(iii) strengthen the guidance of the authorities responsible for road safety, including, perhaps, the creation and strengthening of a structure in the government that acts to coordinate all the actions in the defense of life in traffic across the country.

\section{Acknowledgements}

This project was supported by grants from the Prosecution Service of the Federal District and Territories (MPDFT) and Federal District Research Support Foundation (FAPDF). The authors are grateful to the Civil Police of the Federal District (PCDF) as well as the Traffic Department of the Federal District (DETRANDF), for their precious collaboration to this research.

\section{References}

[1] WHO, Global status report on road safety: supporting a decade of action. World Health Organization, Geneva, Switzerland, 2013.

[2] WHO, Global status report on road safety: time for action. World Health Organization, Geneva, Switzerland, 2009.

[3] Faria, E.O. and Braga, M.G.C. Propostas para minimizar os riscos de acidentes de trânsito envolvendo crianças e adolescentes. Ciênc. Saúde Coletiva 4(1), 95-107, 1999.

[4] Gomes, J.A. and Martins, Z.S. Termo de Cooperação Técnica firmado entre a Fundação de Peritos em Criminalística Ilaraine Acácio Arce, FPCIAA, e o Ministério Púbico do Distrito Federal e Territórios, MPDFT, 2013.

[5] Gomes, J.A., Andrade, A.F.B., Andrade, C.A., Kawano, N.M., Camargo Filho, W.X., Soares, R.M., Vicente, A.N., Sercheli, M.S. and Telles, B., Analysis of fatal vehicle-pedestrian accidents occurred in Brazilian Federal District using police data - Part I. Unpublished Research..

[6] Gomes, J.A., Oliveira, J.L.N., Sercheli, M.S., Kawano, N.M., Camargo Filho, W.X., Soares, R.M., Vicente, A.N., Telles, B. and Andrade, C.A., Analysis of fatal vehicle car crash collisions occurred in Brazilian Federal District using police data - Part II. Unpublished Research.

[7] Ribaux, O., Girod, A., Walsh, S. J., Margot, P., Mizrahi, S., Clivaz, V. Forensic intelligence and crime analysis. Law, Probability and Risk, 2003.

[8] Morelato, M., Beavis, A., Tahtouh, M., Ribaux, Kirkbride, P., Roux, C. The use of forensic case data in intelligence-led policing: The example of drug profiling. Forensic Sci. Int., 226, pp. 1-9, 2013.

[9] Morelato, M., Bachler, S., Ribaux, O., Beavis, A., Tahtouh, M., Kirkbride, P., Roux, C. and Margot, P. Forensic intelligence framework - Part I: Induction of a transversal model by comparing illicit drugs and false identity documents monitoring. Forensic Sci. Int., 236, pp. 181-90, 2014.

[10] Mazerolle, L. and Wortley, R., Environmental Criminology and Crime Analysis, Taylor \& Francis, 2008.

[11] Beato, C.F., Peixoto, B.T., Andrade, M.V. Crime, Oportunidade e Vitimização. Revista Brasileira de Ciências Sociais, 55, pp. 73-90, 2004. 
[12] Clarke, R.V. and Eck, J., Become a Problem Solving Crime Analyst: In 55 small steps. Routledge, 2014.

[13] CONTRAN, Conselho Nacional de Trânsito, Ministério das Cidades. Manual Brasileiro de Sinalização Vertical, Volume IV, Brasília, Brazil, 2007.

[14] CONTRAN, Conselho Nacional de Trânsito, Ministério das Cidades. Instalação de ondulações transversais e sonorizadores - Resolução \#39, Brasília, Brazil, 1998.

[15] Alencar, C.M.S. and Freitas, A.C.B.F., O Comportamento do Condutor Quanto à Velocidade Veicular em Segmentos Adjacentes as Lombadas Eletrônicas em Vias Arteriais: O Caso de Fortaleza. Anais do XVIII Congresso de Pesquisa e Ensino em Transportes ANPET, Brazil, 2004.

[16] DER/SC, Departamento de Estradas de Rodagem de Santa Catarina, Diretoria de Estudos e Projetos. Utilização e Configuração de Rotatórias em Estradas fora de Áreas Urbanizadas (2000). www.deinfra.sc.gov.br/jsp/relatorios_documentos/doc_tecnico/download/e ngenharia_rodoviaria/Utilizacao_Configuracao_Rotatorias_Estradas_Area s_Urbanizadas.pdf

[17] CONTRAN, Conselho Nacional de Trânsito, Ministério das Cidades. Manual Brasileiro de Sinalização de Trânsito, Volume I, Brasília, Brazil, 2007.

[18] CONTRAN, Conselho Nacional de Trânsito, Ministério das Cidades. Manual Brasileiro de Sinalização de Trânsito, Volume II, Brasília, Brazil, 2007. 